\title{
The Influence of Using Minimalist Furniture on the Efficiency of the Living Space - Residential Apartments in Sulaimani City as Case Study
}

\author{
Hazha Mahmood Tahir, Amjad Muhammad Ali Qaradaghi \\ Architecture Department- College of Engineering - University of Sulaimani \\ *corresponding: email :hazhamahmood@yahoo.com
}

\begin{abstract}
:
Raising the figure of population and restricted land for development in Sulaimani leads to the growing of vertical housings and small apartments. Small apartments are a consequence of the continuous growing population and urban housing development. The marketing prices and the growing urbanization oblige folks into less amount of space. Human necessities are still alike or perhaps it is much more than what it used to be. There is a lot of fundamental need to be preserved and achieved to create human wellbeing. The problem of small spaces can be resolved by some ways; however, it is still required for furniture to develop to be more innovative to accommodate small living spaces. Since furniture is a necessity and not luxury, everybody is in need of it. Therefore, living in a small space necessitates minimalist and space-saving furniture solutions to sustain human wellbeing. This paper attempts to explore the Influence of Using Minimalist Furniture on the Efficiency of the Living Space; by means of the variable resulting from preceding studies based on literature had been creating a checklist to measurement minimalist furniture influencing the living space efficiency. This paper concludes that most of the principles of the minimalist approach have been overlooked at, which had an impact on the space efficiency in the living room.
\end{abstract}

Keyword: Living space in a residential apartment, Minimalist furniture.

Paper History: (Received:23-2-2020 ;Accepted:10-5-2020 )

\section{1- Introduction:}

No furniture $=$ no interior, furniture will play a crucial - probably the most crucial - part in the refinement of the new installation and the physical interaction between interior elements and those who use them. The architect Norman Foster has said: "Furniture is like architecture in microcosm." As such, it must bear closer scrutiny than the exterior of any building because those who use it come, unavoidably, into direct visual and physical contact with it and are made more aware of its practical efficiency and of the aesthetic language it speaks [1].

Furniture is an integral element in the design of interior space because it affects human functions and desires, such as sitting, working, sleeping, and relaxing. Furniture also provides the personalization of space as it reflects individual preferences, activities, and needs. Most interior spaces require furniture, which provides the transition between the people and the architecture of the space. Over the millennia, civilizations have witnessed many epochs and styles in both architecture and furniture. Today, as in the past, designers will use a particular style to reflect a client's desired personal or corporate image. Space planners, architects, and interior designers, therefore, need to have a basic understanding of the main attributes and characteristics of these styles in order to better serve their clientele[2].

\section{2- Literature review:}

To specify the research problem statement and the research gap, the following previous studies have been presented:

\section{2-1- The study of (Tan Boon Chai), 2016: New Concept} of Furniture Design by using Space Saving Approach:

This study finds that many people have to live in small spaces, especially in big cities. In the current market, there is available a lot of space-saving furniture suitable to be used to help people for saving living space. Sofa bed also one of the space-saving furniture. Many people dealing with limited areas to force them to more creative to make a small apartment become a comfortable living space. The apartment was divided into the bedroom, bathroom, kitchen and living room. These will make us feel lack out of space for our house. We have to try eliminating some unnecessary furniture and finding the right one would make our house or apartment look more spacious[3].

\section{2-2- The study of (Kristoffer Thogersen), 2016: Small spaces need smart solutions:}

This study points to a significant connection between furniture, small apartments and human wellbeing, as well as the physical surrounding in an apartment having a large impact on its residents. With these two factors in mind when designing furniture for an apartment, the result could end up affecting human wellbeing in a positive way.

Firstly: having a piece of furniture with more than one function is essential to save as much valuable space as possible. Secondly, the arrangement of the furniture could be used to affect the flow and feel of an apartment[4]. 


\section{2-3- The study of (Oday Q. Abdulpader, Omar A. Sabah, and Hussein S. Abdullah), 2014: Impact of Flexibility Principle on the Efficiency of Interior Design:}

The study finds that flexibility in architectural design can solve the area Problems and multi-use plan. It could provide many possibilities to change the shape and size of internal space in addition to the economic and social impacts on the housing system. The increase of moving from the rural and suburban to the main city offset router by new and creative designs and experiences that seek to solve the problems associated with immigration. Because of these necessary needs, designers have started new and creative ideas to design skyscrapers and multi-story buildings to cover the housing and economic needs. These solutions vary mechanism from one area to another mismatch of vertical buildings and use them depends on the reduced space. This research studies the possibilities of flexible designs and the impact on the efficiency of interior design in addition to the using of integrated serves to get a creative and sustainable design to make our city more livable. The principles interior design of the housing unit has a significant effect on increasing or decreasing economic and housing buildings. In this study the principle of flexibility design is studied in two lines:

1- Flexibility plan (space, wall, floor, and ceiling).

2- Flexibility details (furniture) [5].

From analyzing the previous studies and theses, it could be noted that some of the factors which leads to appearing minimalism in interior spaces mentioned, but there was not a specific study which deals with the minimalist furniture and the effect on the efficiency of living room space, therefore, this study tries to fill the scientific gap through achieving a wide range of knowledge and databases on the efficiency of the Living Space Thus, the study reaches to the problem of the research, as:

\section{3- Research Problem:}

Lack of interest in applying the principles of minimalism approach in designing and using furniture in the living room.

\section{4- Research objective:}

To evaluate the importance of minimalist furniture and its role on the efficiency of interior space in small apartments.

\section{5-Research Hypothesis:}

Lack of applying minimalism principles in designing and using furniture elements in the interior design of small apartment projects in Sulaimani City.

\section{6- Definition of Key terms in the research:}

\section{6-1- Living Areas:}

Living room, gathering room, great room, and family room - all of these terms describe a space where people gather to interact and take part in various forms of entertainment, from reading to computer work/games and television viewing. For many current homeowners, a formal living room "where no one ever goes "is no longer desired. Instead, a great room or gathering room where all family members can gather and take part in a range of activities is preferable. However, some homeowners do still desire a room for more formal events, and there may be a desire for a room used for the adults in the family, with younger family members using a separate room-often called a family room or den. Similarly, formal dining rooms are not favored by some current homeowners; these people often prefer a more casual eating area that is open or partially open to the kitchen, forming cooking, eating, and entertainment area. Another function of a living room is as a space to mingle and spend time with family. As a main gathering space in the house, the living room allows family members to get together and join in a range of activities desirable [6]. Family members have the opportunity to spend quality time together with a variety of activities such as watching television, talking about their day and playing video games. Different activities require different furniture spatial arrangements to suit their needs. As a space for informal time with loved ones, a different level of intimacy is provided in a living room [7]. Even the smallest of living areas benefit by having the spaces separated into sections for different activities. Within the living space, three activity areas might be a primary seating/conversation area, a secondary seating group, and an entertainment center. The functions of these areas can also overlap rather than being distinctly separated. The primary seating area is usually the major conversation space, with the furniture grouping or a focal point (such as a fireplace or television) being the dominant element [2].

\section{6-2- Minimalist Furniture:}

Furniture is an integral element in the design of an interior space because it affects human functions and desires, such as sitting, working, sleeping, and relaxing. Furniture also provides the personalization of a space as it reflects individual preferences, activities, and needs. Most interior spaces require furniture, which provides the transition between the people and the architecture of the space [2]. Furniture is the generic noun for the movable articles which are implemented in making rooms, alternatively, building appropriate for living or working in, that's how to say, tables, chairs, or desks. The primary reason for making use of furniture in housing is meeting the need for indispensable activities flexibly. Examples of these necessities can be consuming, sleeping, storage, mental and physical efforts as well as sitting and relaxing. The main aim is to address human needs, based on climbing the value of the product because of the usability 
of function; measurement has to correspond to the size of the objects which the furniture of the human and storagedisplay function. Simplification and Minimalist attitude consist of design furniture in plain geometric forms like the other elements. The demand for Simplification of everything in both simplicity and minimalist attitude on interior arrangement draws the attention to the refining and goes back to the basic objects. They are recommended accessories that focus on the functionality with simple and straight lines without ornamentation [8].

\section{There are four main types of minimalist furniture:}

\section{6-2-1 Fixed Furniture:}

In Minimalist dwellings, storage has to be responded by firm furniture like wardrobes cabinets, shelves, and niches. These wardrobes, designed as concealed and stabled in the walls such as niches. In oldfashioned Japanese dwelling, stabled furniture is designed as an architectural element. Stabled furniture supplies most of the storage necessity in minimal spaces; since it is not mandatory to bring additional storage elements into space. Accordingly, space is not taken up with negligible elements. Built-in furniture will let users to define and provide vacant spaces as well as the activities of the user. These vacant spaces which left to the user in building, for the deficiency of any element that restricts it, flexible to changes in life it also supplies elastic spaces. Fixed furniture on the whole need to be compatible in located areas that are designed. It is crucial to be advantageous quite long with regards to flexibility [9].

\section{6-2-2 - Moveable Furniture:}

Movability might be the most vital characteristic of the equipment which is simple and minimal housing. Simple and Minimal places take the advantage of mobility, particularly in spaces which have miscellaneous functions which overlap, moveable furniture makes likely the realization of functions at different times. Mobility, allows you to push, pull, or relocate the furniture from the area so as to be available for other functions. At the end of the implemented function movable furniture supplies perpetual possibilities in a certain space. Contemporary's and modern minimalist attitude provides users to replace heavy and nonessential interior elements as a design principle. Moveable furniture as a part or as a whole need to be light to be carried. Furthermore, these features need to be used to flexible and multifunctional feature. In minimalist spaces to supply multi-functionality in space, particularly the middle part of the space needs allow space and furniture that is not used need to be relocated effortlessly. Accordingly, in minimalist attitude, they referred to apply plain and less heavy so that it will be easy to carry and transportable furniture. For instance, living space can be converted into a sleeping area. Employing space as multi-functional supplied modular interior elements as well [10].

\section{6-2-3- Modular Furniture:}

Modular furniture is extremely precious in particular in less spacious spaces, these interior elements allow users to define and perform more than one activity in a single space. Multi-functionality reinforced with modular elements. Modularity consisted of multi peace which has conventional size sizes and serves a variety of functions based on the demand of the users; these interior elements can also be converted into various interior elements with no trouble. Modularity allows users to define functions, this case can be defined as; same kind elements which are related to each other side by side and serve functions by being mixed and serve unity to the same element. [11].

\section{6-2-4- Pliable Furniture:}

The pliability of furniture can be described as "usage of furniture in different functions, easily collectible and storable". An element that we can recognize as pliable furniture need to imitate the idea that providing solution and meeting needs in a space that activities turn to become intricate. That is to say, pliable furniture needs to assist multi-functionality to accomplish more than one activity in a single space and supply the elasticity of space[10]. Merging more than one function in furniture generates multi-functionality. For instance, tables can enlarge consistent with the basic needs of human like sitting, studying and consuming; moreover, feet of tables can be employed in place of a box for storage. The basic principle is the re-usage of death spaces in the structure of furniture. Simplicity that comes out with multi-functionality is an exhibition of minimalist attitude in the dwelling. In the design process of interior elements, designers may need to ponder about all the volume of furniture rather than the functional portion. Flexibility notion in furniture, offers less usage of off interior elements in space [8].

\section{6-3- Characteristics of Minimalist Furniture:}

\section{6-3-1- Omit needless furniture:}

Since minimalism is a way to escape the excess around us through the reassessment of priorities. The term minimalist often colloquially refers to anything that is spare or stripped to its essential quality. It favors a moderate approach to achievement of a set of goals and offers no more than what is required or essential, a style in which the simplest and fewest elements are used to create the maximum effect. Minimalism is a tool that allowed us to simplify our lives by stripping away the excess stuff so we could focus on what's truly important. "Minimalism in interior space brings new quality: in the first place it cleans space from unnecessary elements and acts very softly and neutral to context of its implementation without visually violating the environment [12]. 


\section{6-3-2- Furniture Arrangement:}

The way furniture is arranged in a room will affect how the space is used and perceived. Furniture can simply be placed as sculptural objects in space. More often, however, furniture is organized into functional groupings. These groupings, in turn, can be arranged to organize and structure space. Most furniture consists of individual or unit pieces that allow for flexibility in their arrangement. The pieces are typically movable and may consist of various specialized elements as well as a mix of forms and styles. Built-in arrangements of furniture, on the other hand, help retain more open space. There is generally more continuity of form among the furniture elements with fewer gaps between them [13].

\section{6-3-3-Functional Requirements:}

Function can be defined as realization of task or purpose. Everything in a minimalist space is functional; everything has to serve a purpose not stand for ornamentation or decoration. Anything that inessential, gratuitous and purposeless can't take place in a minimalist space. Removing inessential and purposeless ornamentation revealing what is functional. This also leads to the essence of space and achieved to simplicity [8].

\section{6-3-4- Furniture Organization and Circulation:}

Circulation and flow through living spaces is dependent upon the relationship of doors and the related circulation patterns that flow from doors and doorways to adjacent rooms, spaces, and furnishings. Simply, the locations of doors/passageways influence the flow through a living space and the related arrangement of furnishings and space efficiency [14].

\section{6-3-5- Easily storable and Space saving:}

The designs of space saving furniture pieces not only make them transformable and space saving but are also aesthetically pleasing and resemble works of art. Transformable space saving furniture is a revolution in furniture design. Since transformable space saving furniture is new, it possesses much room for innovation in both its design and on the future market [15]. Saving furniture provides small properties with greater space and multiple functions, furthermore, transformable space saving furniture can be made more effective and make efficient use of the smallest spaces.

\section{6-3-6- Sustainability in Furniture's Design:}

Furniture is the major element in interior design. They have a wide range of materials and color. In the context of sustainability, materials used in the Furniture produced from waste sometimes face with the problem of aesthetics. These type of furniture are sometimes considered as unaesthetic. This is the major problem in selecting this furniture. The aesthetic quality of the furniture should be considered. Then, it will both serve for the purpose of sustainability and widely used.[16]. After the Industrial Revolution, consuming the natural sources insensibly more than it was needed and the negation that technological growth created gave the environment a harmful ground. These problems got the attentions of the designers and they looked for other ways. The increasing problems of today have made the furniture designers search for new seeking. In environmental problems, there have been two different attitudes:

- The first approach is using the natural materials.

- The second one can be seen as using the recyclable materials.

\section{6-3-7- Furniture Color:}

Color is very powerful design elements that can change perception or use of a space. When we are limited with space, material and beget that make designer to create confinements projects, the only elements that can help, is color [17]. A designer can think about color in two ways: as design or as decoration. Color as design modifies or defines form. It can express history, shape or deepen space, add density, define edge, turn corners. Color as a design element cannot be formulaic, it does not use color in specific terms (red, blue, or yellow) bur rather in terms of what different tonal contrast can do to change a space. Color used as decoration employs specific color to create style. For example, it might deal with a specific fabric that could be enhanced by a particular wall color.

Color as decoration uses aspects of history or recreate a feeling. It finds the metaphors in color and provides impact" [18].

\section{7- The Methodology:}

Defining Minimalism or something minimal such as a building, painting, furniture or an object by your own and evaluating these objects in terms of Minimalism to decide how much minimal is that object is hard, in this subject, there are not any precise and clear criterion furthermore, and these criteria can

changed according to different point of views. For this reason, at first sight, it seems easy to find Minimalism approach by checklist form method. However, at this point in the selection process of buildings it becomes very important. Chosen examples have to make appropriate terms of evaluating values.

To test the research hypothesis, the research depends on the Inductive methodology through methods which prepares a checklist that includes some questions based on the indications and used terms in the theoretical part of the research, shown in table (1) 
The checklist form includes the following axes: -

- The axis about sofa types.

- The axis about furniture arrangement.

- The axis about minimalist furniture types.

- The axis about furniture function.

- The axis about furniture finishing.

- The axis about furniture size.

- The axis of furniture color.

- The axis about flexibility in furniture design.

- The axis about sustainability in furniture.

- The axis of durability and maintenance of the furniture.

- The axis about storability.

- The axis of furniture material.

\section{8- The Research Limitation:}

The research attempts to study some important scope of works in interior space which is (Minimalist furniture). The research seeks to find the causes that rarity and lack of clarity over the rate of using minimalist furniture in the living area of the small apartment projects, which the floor area less than $100 \mathrm{~m}^{2}$ and built during the time period of (2003-2016).

\section{9- The case study:}

When its minimal simplicity is in the interior space, the first small residential buildings come to mind. For this reason, in the evaluation and analysis part of this research, examples of small apartment buildings, which included apartments less than 100 square meters, were chosen. In this research, 96 apartments were selected from the smallest different residential complexes and examined for their minimalist furniture in the living room.

Table (1) Checklist: for sample No.1 (Source: Researcher)

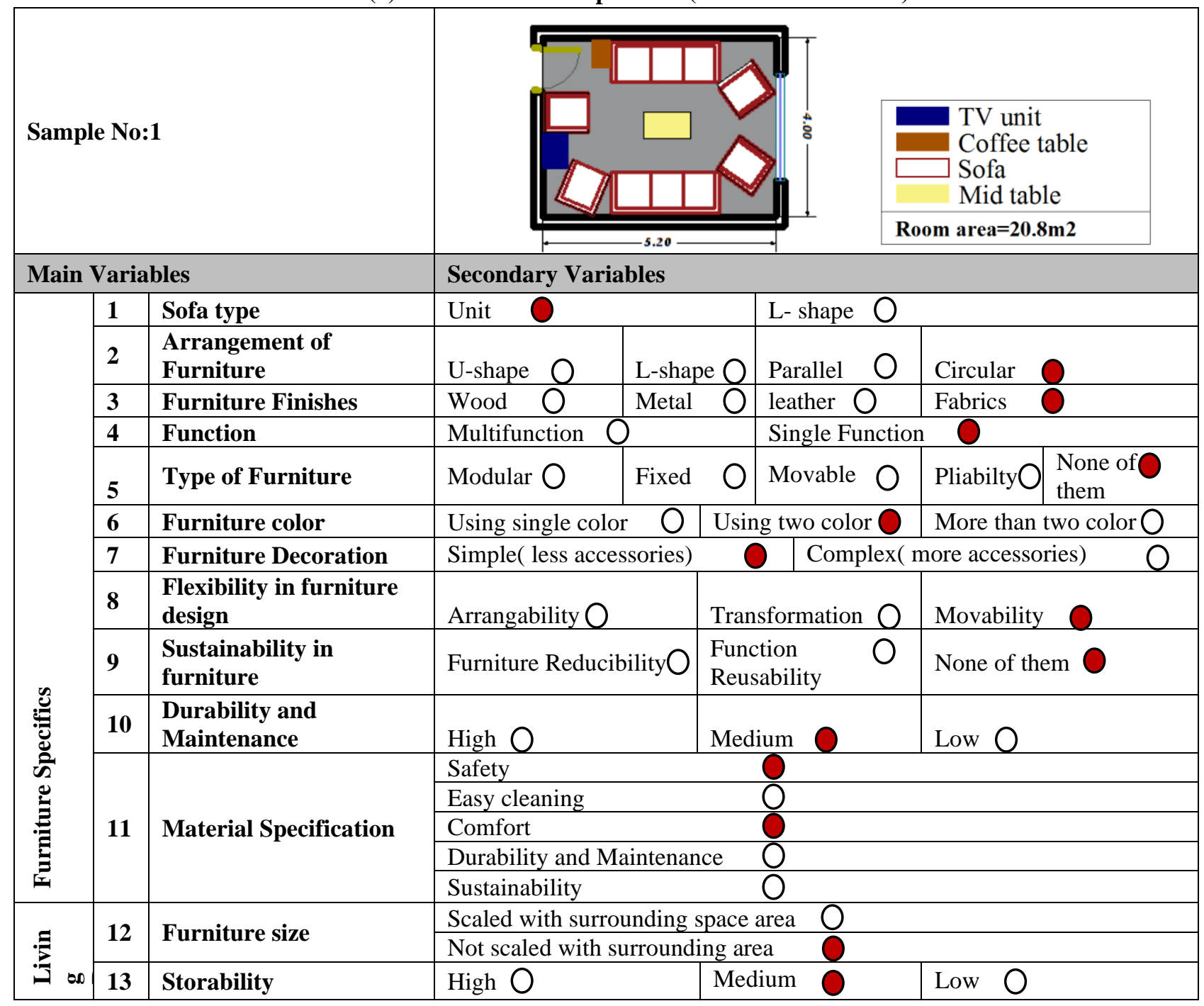




\begin{tabular}{|l|l|l|l|l|l|}
\hline \multirow{2}{*}{$\mathbf{1 4}$} & $\begin{array}{l}\text { Adequacy between } \\
\text { furniture and Living } \\
\text { room }\end{array}$ & Dimension $\mathrm{O}$ & Size $\mathrm{O}$ & Shape \\
\cline { 2 - 5 } & $\mathbf{1 5}$ & $\begin{array}{l}\text { Circulation between the } \\
\text { furniture in living room }\end{array}$ & Furniture arrangement allowing free movement and circulation & Furniture arrangement restricting the movement \\
\hline
\end{tabular}

\section{0-Data analysis:}

- The outcome analysis of the Furniture type shows that $64.6 \%$ of the selected samples used the unit sofa, and
$35.4 \%$ used L- shape sofa as shown in figure (1-A, B, C), which indicates that most of the residents prefer unit type more than L-shape.

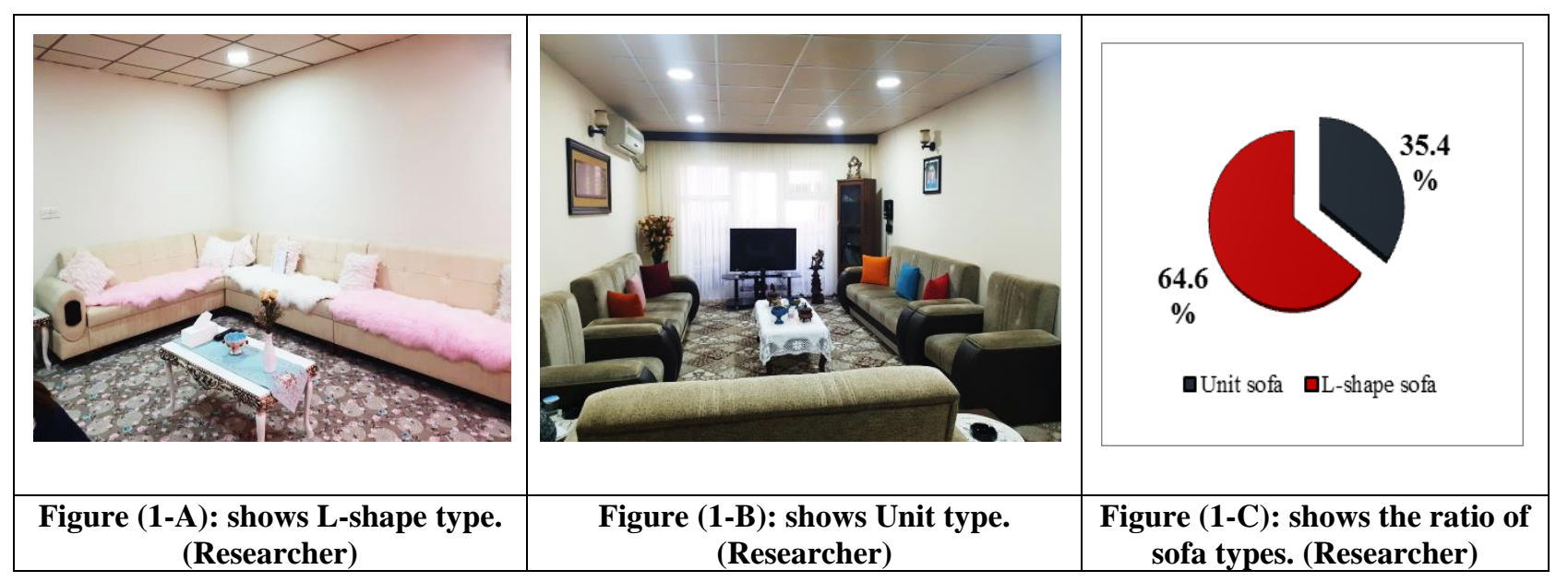

- As for the arrangement of furniture, the results demonstrate that the range for $\% 40$ of the selected samples is U-shape type, \%38 is L-shape, \%21 is parallel type and $\% 1$ is circular type, shown in figure (2-A, B, C, D).

\begin{tabular}{|c|c|c|}
\hline & Figure (2-B): shows Parallel arrangement \\
(Researcher)
\end{tabular}




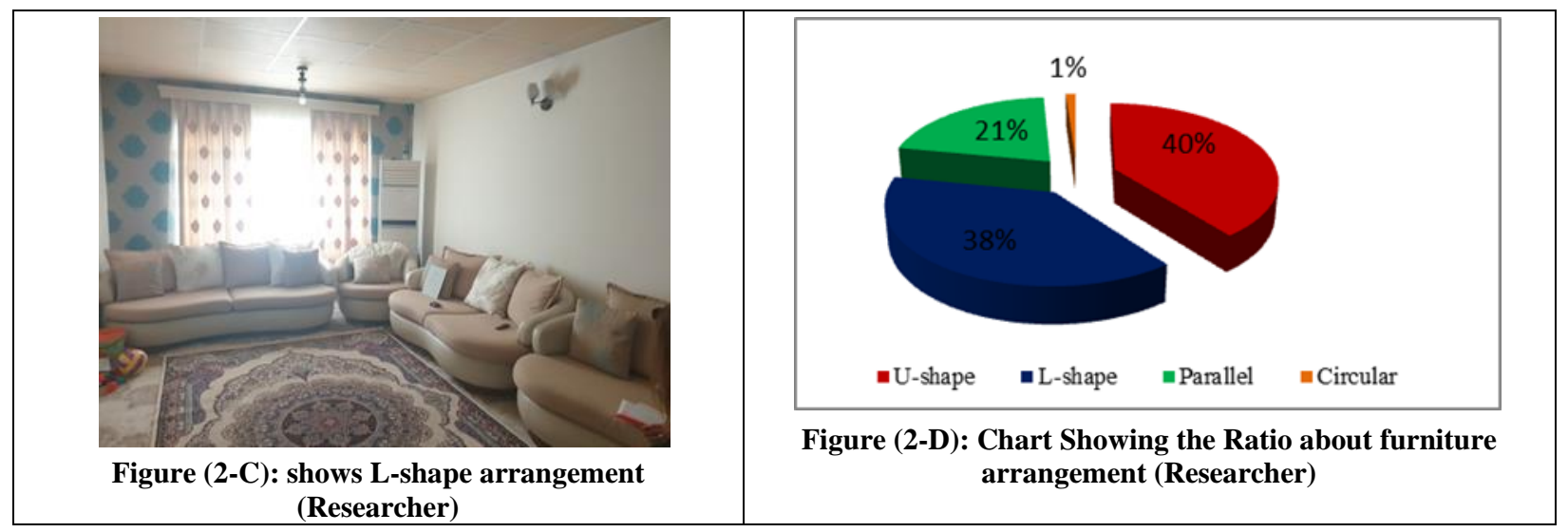

- Regarding the finishing material of furniture, most of the furniture is fabric type then leather and metal type.

- The results show that, most of the furniture has single function only $\% 10$ of the selected samples has multifunction.
- A small portion of the furniture is minimalist, which is $\% 40$ of them is fixed type, $\% 30$ is pliability, $\% 20$ is modular and $\% 10$ is movable type.

- Using one Color is one of the most important characteristic of the minimalist approach; the finding of the research represents that only $\% 9$ of the selected samples is one color. shown in figure (3-A, B, C).

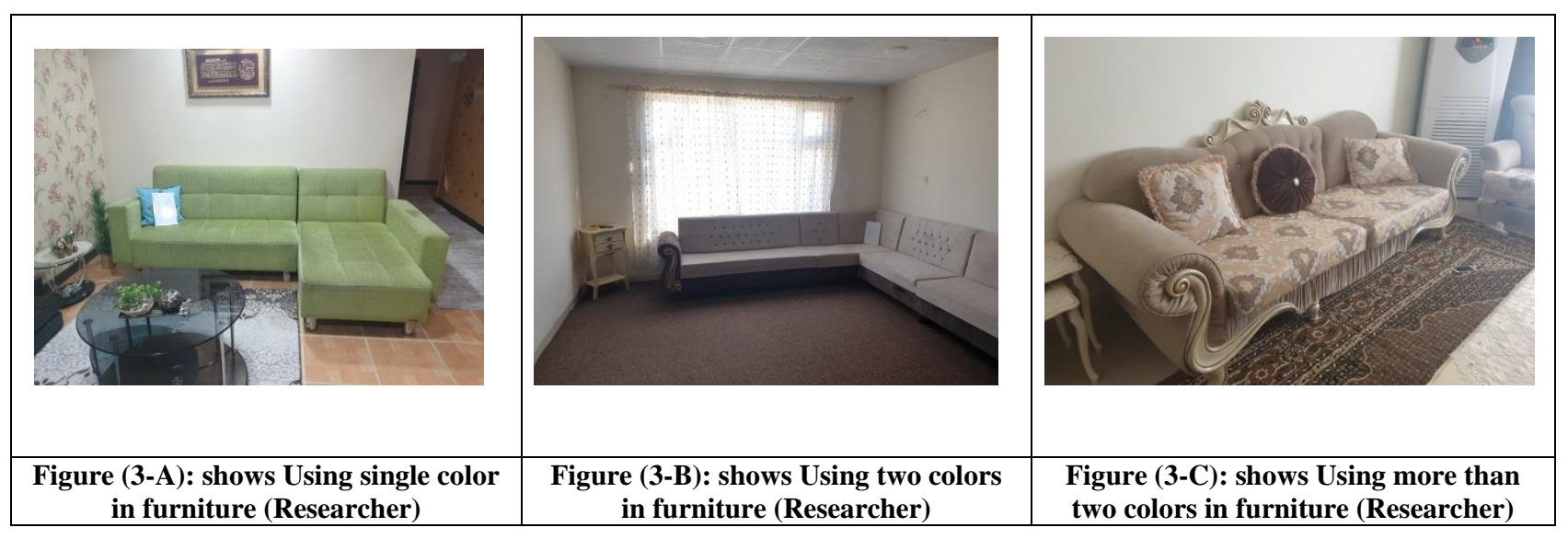

- Regarding the rate of simplicity and complex of furniture, the research shows that $\% 52$ is contained more accessories (complex) and \%48 is simple which contains less accessories and decoration. shown in figure (4-A, B, C)

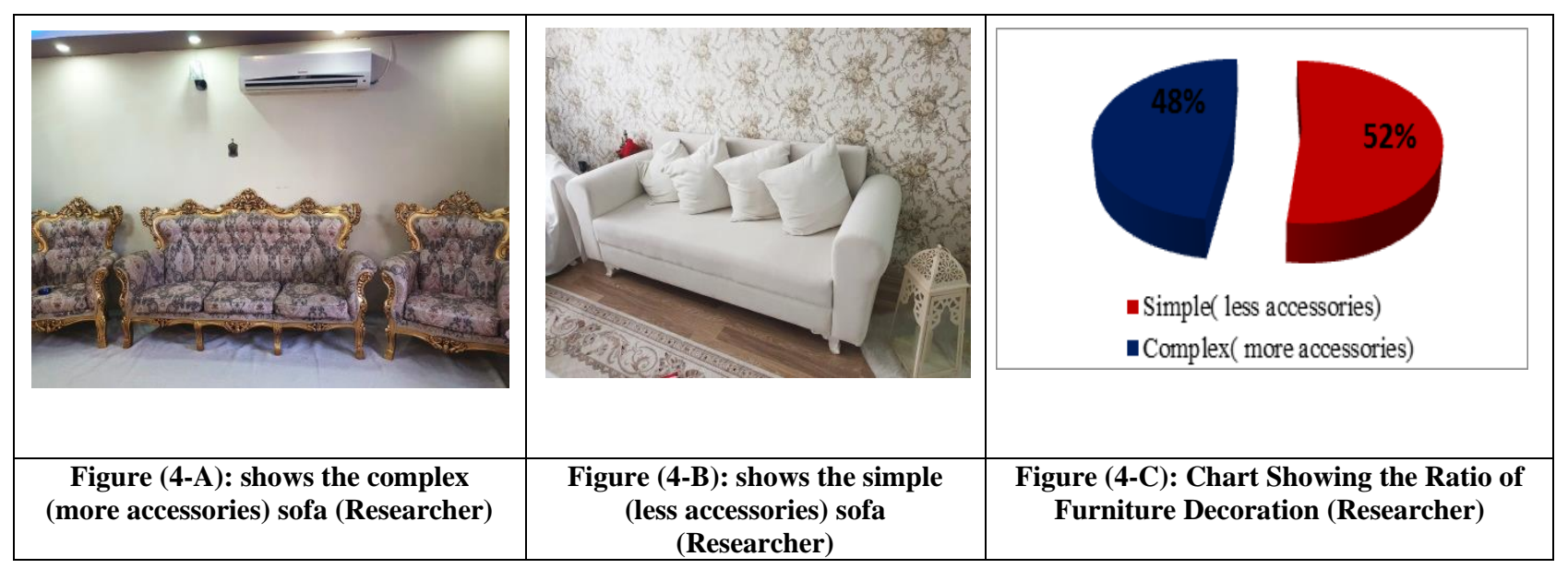


- Regarding the characteristics that create flexibility in the selected furniture, $82 \%$ is by movability, $13 \%$ is by Arrangability and $5 \%$ is by transformation.

- $\quad$ Regarding the achievement of sustainability principle of furniture in the selected samples, $32.4 \%$ is sustainable through achievement of (function reusability and furniture reducibility) principles and $\% 67.6$ is not sustainable.

- The results demonstrate that the rate of durability and maintenance of the furniture is very low which is reached to $70.8 \%$ of the selected samples.
- The research shows that the safety and comfort property have priority to the easy

- cleaning and durability in selecting furniture by the residents.

- Regarding the scale of the furniture compared with the surroundings, the results shows that $\% 53$ is scaled with the surrounding space area and $\% 47$ is not scaled with it. shown in Figure (5)

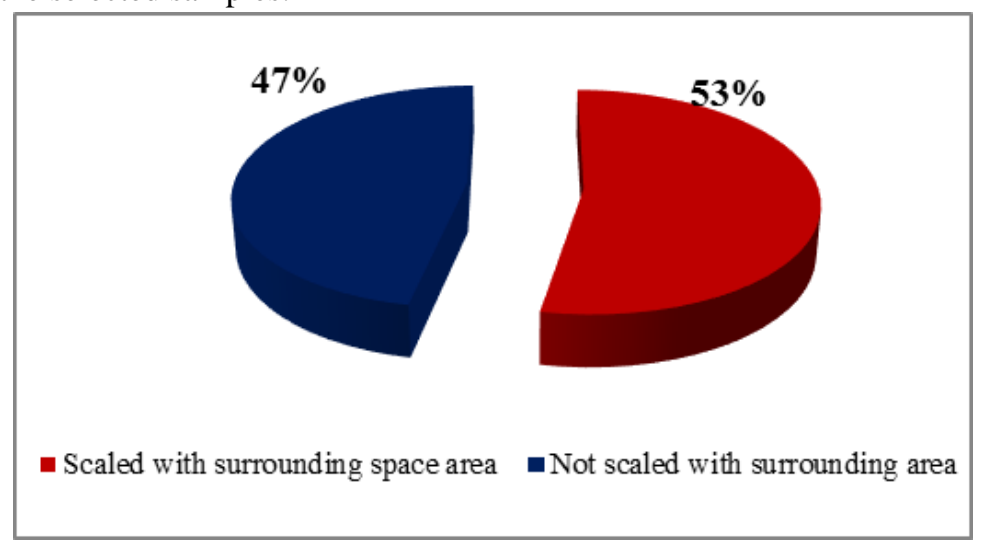

Figure (5) Chart Showing the Ratio of Furniture size (Prepared: Researcher)

- Regarding the factor of storability of the space on the base of the remained area, the rate of the storability is very low in the selected samples.

- Regarding the effect of the furniture on the circulation inside the living space, the result shows that $43.7 \%$ of the selected samples, the furniture make obstacle to the circulation which is a dangerous rate for losing the efficiency of the interior spaces. Shown in

- $\quad$ Figure (6-A, B)

- The Shape of the furniture has the great role to create adequacy in the living room more than the other factors like size and dimension.

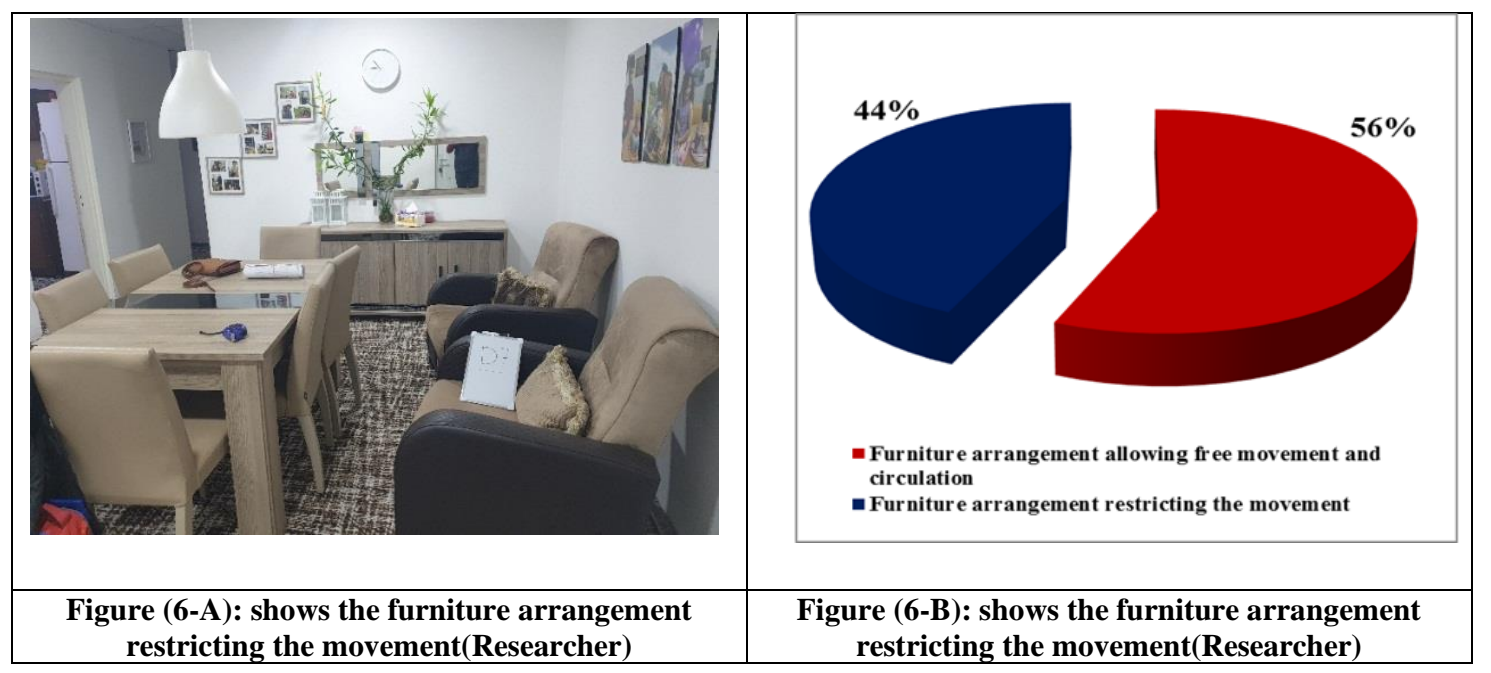




\section{Conclusions:}

1. The findings of the research show that the types of sofas placed inside a high number of apartments are unit type. This indicates that one of the important principles of the minimalism approach has not been considered.

2. Regarding the consideration of the "arrangement of furniture", this factor, as one of the principles of minimalism, has been relatively applied as most furniture is U-shaped which has met the interaction requirements.

3. Most of the furniture is not multifunctional, leading to a lack of application of the minimalist approach.

4. Most of the furniture is fixed-furniture and they are not movable.

5. The scale of the furniture is proportional compared to the scale of the surrounding space. This has come closer to the implementation of the minimalism.

6. More than two colors have been used in most of the sampled furniture of the apartments, which made us farther from the principle of minimalism.

7. Most of the furniture is of complex type as many accessories have been used in their design.

8. The arrangement factor has been less considered compared to the movability.

9. The sustainability principles in terms of the furniture reducibility and functional reusability have not been applied.

10. Regarding the storability, most of the furniture is not storable.

11. Safety and comfortability have been paid more attention than easy cleaning, durability, and maintenance.

12. A number of furniture created obstacles to the circulation in the living room space.

13. The above findings show that most of the principles of the minimalism approach have not been considered, which affected the space efficiency in the living rooms.

\section{References:}

Book:

[1]. Sam Booth and Drew Plunkett "Furniture for Interior Design",2014.

[2]. Rosemary Kilmer, \& W. Otie Kilmer. "Designing interiors"- 2nd ed,2014.
[6]. Maureen Mitton, Courtney Nystuen "RESIDENTIAL INTERIOR DESIGN", 2007.

[11].Yagi, K. "A Japanese Touch for Your Home", Tokyo \& New York, Kodansha International, 1992.

[12]. Bruci. Allsopp, "A modern Theory of Architecture", Routeladge and Kegan Paul, 1977.

[13]. Francis D.K. Ching \& Corky Binggeli "INTERIOR DESIGN ILLUSTRATED”, Third Edition ,2012.

[14]. Mark Karlen\& Rob Fleming "Space Planning Basics", 4th Edition,2016.

[17]. John Pile, "Colors in interior design, New York", 1997.

[18]. Ladau R., Smith BK \& Place J. "Color in Design and Architecture", New York, Van Nostrand Reindhold, 1989.

Thesis:

[3]. Tan Boon Chai, "NEW CONCEPT OF FURNITURE DESIGN BY USING SPACE SAVING APPROACH", 2016.

[4]. Kristoffer Thogersen, "Small spaces need smart solutions",2016.

[5]. Oday Q. Abdulpader, Omar A. Sabah, and Hussein S. Abdullah, "Impact of Flexibility Principle on the Efficiency of Interior Design",2014.

[8]. Nergiz, F., "Study of Design Properties and Visual Qualities of Minimalist Space with the Basic Elements of Architecture on the Typology of House", İstanbul, I.T.U ,2005.

[9]. Irmak, C.H. "Simplicity and Minimalist Attitude in Architecture”, İstanbul, I.T.U ,2002.

[16]. Nur Ayalp, "Environmental Sustainability in Interior Design Elements”,2017.

Paper in a journal:

[7]. Rechavi, T. B. "A room for living: Private and public aspects in the experience of the living room". Journal of Environmental Psychology, 2009.

[10]. Ökem, S. "Furniture in Minimal Houses", Journal of Architects, 2001.

[15]. Shiyao Wang, "An Analysis of Transformable space saves Furniture”, 2013. 